\title{
Effects of high- and low-fat meals on the diurnal response of plasma lipid metabolite concentrations in healthy middle-aged volunteers
}

\author{
BY D. L. FRAPE ${ }^{1}$, N. R. WILLIAMS ${ }^{2}$, A. J. SCRIVEN ${ }^{2}$, C. R. PALMER ${ }^{3}$, \\ KATHRYN O'SULLIVAN ${ }^{4}$ AND R. J. FLETCHER ${ }^{4 *}$ \\ ${ }^{1}$ N.S. Research, The Priory, Mildenhall, Suffolk IP28 7EE \\ ${ }^{2}$ Pathology Department, Papworth Hospital, Papworth Everard, Cambs CB3 8RE \\ ${ }^{3}$ University of Cambridge, Department of Community Medicine, Institute of Public Health, Robinson Way, \\ Cambridge CB2 2SR \\ ${ }^{4}$ The Kellogg Company of Great Britain Ltd, The Kellogg Building, Talbot Rd, Manchester M16 OPU
}

(Received 23 November 1995 - Revised 20 May 1996 - Accepted 3 July 1996)

\begin{abstract}
Three experiments were conducted in healthy middle-aged volunteers (six males and six females in Expt 1, six males and two females in Expt 2 and twelve males in Expt 3) with a mean BMI of $27 \mathrm{~kg} / \mathrm{m}^{2}$ to determine whether there is a difference between morning and afternoon dietary fat clearance and utilization, and to determine in what way the fat and starch contents of the meal influence postprandial blood lipid metabolites over $4.5 \mathrm{~h}$. Over 4 days in Expt 1 each subject received isoenergetic, high-carbohydrate ( $\mathrm{L}, 5.5 \mathrm{~g} \mathrm{mixed} \mathrm{fat} / \mathrm{meal})$ and moderately high-fat $(\mathrm{M}, 33 \mathrm{~g}$ mixed fat/meal) breakfasts and lunches, in three combinations (LL, MM, LM), or they fasted at breakfast time and received a high fat lunch (NM) in a randomized and balanced arrangement. Each evening a standard meal was given. The following effects were significant $(P<0.05)$ : plasma triacylglycerol (TAG) responses were greater following $M$ meals; plasma TAG concentrations were greater in the afternoon than in the morning, following two meals of the same composition, although the postprandial incremental response was less following lunch than following breakfast and peak responses were reached much earlier than after breakfast; a low-fat breakfast, or fasting at breakfast time, delayed the peak TAG response to a $M$ lunch. The plasma concentrations of nonesterified fatty acids (NEFA) and of free glycerol were higher in the afternoon following $M$ meals at breakfast and lunch, especially in males. This response was reduced, by the $L$ breakfast preceding the $M$ lunch. Two $M$ meals in succession lowered plasma HDL-cholesterol concentration. In Expt 2 each subject received a very low-fat (VL) breakfast, followed by a lunch of the same composition. Each of these meals was followed, $110 \mathrm{~min}$ from the start of eating, by an infusion of Intralipid $10 \%$ emulsion at the rate of $1 \mathrm{ml} / \mathrm{kg}$ body weight over $60 \mathrm{~s}$. Clearance rates of Intralipid were faster in the afternoon than in the morning $(P=0.024)$. In Expt 3 twelve subjects were randomly allocated to either treatment MM or LM meal patterns, as given in Expt 1. These were given daily for a period of $17 \mathrm{~d}$, during which the change in fasting plasma TAG concentration was similar in both treatments. On days 1, 16 and 17 responses were measured to the $M$ lunch and to a glucose tolerance test (GTT), conducted $2 \mathrm{~h} 17 \mathrm{~min}$ after lunch. The post-lunch responses confirmed those found in Expt 1; but immediately following the glucose dose there was an abrupt increase in plasma TAG that was greater in treatment $\mathbf{L M}$ than in treatment $M M(P=0.025)$, whereas plasma NEFA concentration decreased rapidly in both treatments at that time $(P=0.00066)$.
\end{abstract}

Dietary fat: Dietary carbohydrate: Triacylglycerols: Non-esterified fatty acids 
Elevated fasting concentrations of plasma triacylglycerol (TAG) tend to be associated with an elevated postprandial TAG response, insulin resistance, a low plasma HDL-cholesterol concentration and atherogenesis (Baggio et al. 1980; Barbagallo et al. 1991; Frape \& Jones, 1995). The combination of elevated serum TAG and low serum HDL-cholesterol concentrations is associated with a poor chronic clinical prognosis following coronary bypass surgery (Lindén et al. 1994). Elevated postprandial plasma TAG concentrations may promote insulin resistance by an associated release into the plasma of non-esterified fatty acids (NEFA). High concentrations of NEFA in contact with isolated hepatocytes have been demonstrated to impair insulin binding (Svedberg et al. 1990, 1991), impair dietary glucose oxidation through the glucose-NEFA cycle (Randle et al. 1963) and increase hepatic gluconeogenesis. High-fat, low-carbohydrate diets have been used traditionally to induce insulin resistance in laboratory animals. Such diets, compared with isoenergetic high-carbohydrate diets, have induced resistance within $\mathbf{3} \mathrm{d}$ in healthy volunteers (Sidery et al. 1990) and in rats (Smith, 1994). However, Chen et al. (1993) showed that the replacement of saturated fat by carbohydrate increased postprandial lipaemia, the extent of which was correlated with insulin response in patients with noninsulin-dependent diabetes (NIDDM), and replacement of fat with carbohydrate has been shown to increase fasting plasma TAG and lower plasma HDL-cholesterol concentrations (Smith, 1994). Thus, it is not certain that dietary carbohydrate is to be preferred to mixed fat in the prevention of heart disease and insulin resistance.

Two hypotheses were tested in the present experiments in healthy middle-aged subjects: (1) that a moderately fatty meal causes a higher postprandial plasma TAG response than a carbohydrate meal providing a similar amount of metabolizable energy $(\mathrm{ME})$ and (2) that there are differences in acute postprandial plasma lipid responses to meals of similar composition taken at breakfast and lunch time. In order to explain the expected differences two further hypotheses were advanced: (3) that any differences found in (2) might be related to differences between morning and afternoon in the clearance rate of intravenously administered fat and (4) that postprandial metabolic effects occurring after lunch could be attributed to the combined effects of meals at both breakfast and lunch time. The meals were typical of traditional fatty and cereal breakfasts.

\section{MATERIALS AND METHODS}

Expt 1

Three blocks of four healthy volunteers each (six males, six females) were tested over a $4 \mathrm{~d}$ period in an experiment of randomized and balanced design with each subject receiving the four treatments over $4 \mathrm{~d}$, and in which these treatments were imposed at breakfast and lunch time only. The treatments consisted of meals of two compositions, providing similar amounts of ME: moderately high-fat, low-carbohydrate $(M)$ or moderately low-fat, highcarbohydrate (L). An alternative treatment was no breakfast $(\mathrm{N})$ and a $\mathrm{M}$ lunch. The resulting combinations of breakfasts and lunches were LL, MM, NM and LM and their composition is given in Table 1 . The meals were given at 08.30 hours and 13.00 hours.

Orange juice was given to subjects in Expt 1, except the fasted subjects, and was consumed in $30 \mathrm{~s}$ before the remainder of each meal. The fasted subjects received $150 \mathrm{ml}$ water at breakfast time. Both breakfasts and lunches were consumed in an average of 10 min. The lunch was followed by a standard evening meal at 18.15 hours, which provided 4.5 MJ ME, and comprised beefburger, three vegetables, yoghurt, and weak coffee, after which there were no postprandial measurements. A soft drink, half a pint of beer, or equivalent, was permitted between 19.00 hours and 20.00 hours daily. No other 
Table 1. Mean analysed composition of the cereal and omelette meals in Expt 1 and of the total daily intake during days 2-16 in Expt 3*

\begin{tabular}{|c|c|c|c|c|}
\hline & \multicolumn{2}{|c|}{ Expt 1} & \multicolumn{2}{|c|}{$\begin{array}{c}\text { Expt } 3 \\
\text { Total daily intake days } 2-16\end{array}$} \\
\hline & Cereal meal, $\mathrm{L}^{\dagger}$ & Omelette meal, $\mathbf{M} \dagger$ & $\mathbf{L M}$ & MM \\
\hline Energy (MJ, ME†) & 2.1 & $2 \cdot 2$ & 10.6 & 10.7 \\
\hline Fat $(g)$ & 5.4 & 32.9 & 105.6 & $133 \cdot 1$ \\
\hline Saturated fatty acids (g) & $3 \cdot 0$ & $16 \cdot 0$ & $50 \cdot 2$ & 63.2 \\
\hline Monounsaturated fatty acids (g) & 1.7 & 11.8 & $42 \cdot 5$ & 52.6 \\
\hline Polyunsaturated fatty acids $(\mathrm{g})$ & 0.5 & 4.0 & 12.7 & $16 \cdot 2$ \\
\hline Protein (g) & 17.9 & $29 \cdot 3$ & $69 \cdot 2$ & $80 \cdot 6$ \\
\hline Dietary fibre $(\mathrm{g})$ calculated & 0.9 & 0.4 & 1.9 & 1.4 \\
\hline Energy from $\mathrm{CHO}(\%)$ & 74.7 & 20.7 & $48 \cdot 1$ & 37.4 \\
\hline Energy from fat $(\%)$ & $10-9$ & 57.3 & $36 \cdot 8$ & $46 \cdot 1$ \\
\hline
\end{tabular}

L, high-carbohydrate meal; M, moderately high-fat meal; LM, high-carbohydrate breakfast and moderately high-fat lunch; MM, moderately high-fat breakfast and lunch; ME, metabolizable energy; $\mathrm{CHO}$, carbohydrate.

*For details of experiments, see pp. 376-378

$†$ The cereal meal consisted of: pure orange juice $150 \mathrm{ml}$, cornflakes $86 \mathrm{~g}$, semi-skimmed milk $300 \mathrm{ml}$; the omelette meal consisted of: pure orange juice $150 \mathrm{ml}$, omelette (containing egg, ham, butter in a fried potato casing) $192.7 \mathrm{~g}$.

$\$$ Calculated from the protein, fat, starch and sugar contents determined. The energy contents of meals $\mathrm{L}$ and $\mathrm{M}$ eaten in Expt 3 were 1.81 and $1.89 \mathrm{MJ} \mathrm{ME}$ respectively, owing to omission of the orange juice.

stimulating drink, or tobacco, was permitted during the course of the study. All subjects received $150 \mathrm{ml}$ carbonated water $2 \mathrm{~h} 5 \mathrm{~min}$ after the commencement of both breakfast and lunch.

The composition of the meals was determined by chemical analysis after preparation for eating (Table 1). The fatty acid composition of the fat in the $M$ and $L$ meals was very similar, predominately dairy fat, demonstrated by analysis. The methods of food analysis were those used by Frape \& Jones (1995).

\section{Expt 2}

Eight subjects (six males, two females) took part in a study to compare the clearance rate of lipid (Intralipid $10 \%$ emulsion, Kabi Pharmacia Ltd, Milton Keynes, Bucks.) during the morning with that during the afternoon of the same day, within-subject. The lipid was infused into an antecubital vein at the rate of $1 \mathrm{ml} / \mathrm{kg}$ body weight over $60 \mathrm{~s}$. Each subject received Intralipid from the same bottle morning and afternoon. Infusion commenced $110 \mathrm{~min}$ after the start of the consumption of a very-low-fat meal, composed of $60 \mathrm{~g}$ wheatflakes and $225 \mathrm{ml}$ skimmed milk, at 08.30 hours and again at 13.00 hours. The mean ingestion times for breakfast and lunch were approximately $6 \mathrm{~min}$. Immediately following each clearance test subjects received $150 \mathrm{ml}$ water.

\section{Expt 3}

In this experiment treatments $\mathrm{MM}$ and LM of Expt 1 were repeated in a completely randomized design with twelve middle-aged male volunteers allotted at random from pairs of similar body weight to either LM or MM treatments. The subjects received their respective treatments from day 2 to day 17 of a $17 \mathrm{~d}$ period, during which all meals were 
provided. On day 1 all subjects were given treatment LM and in the analysis of treatment differences the postprandial responses to lunch on day 1 were subtracted from the equivalent responses to lunch on the mean of days 16 and 17 . In addition on days 1,16 and 17 a glucose tolerance test (GTT) was carried out commencing $2 \mathrm{~h} 17 \mathrm{~min}$ after the start of lunch, when $82.5 \mathrm{~g}$ glucose monohydrate (equivalent to $75 \mathrm{~g}$ glucose), in approximately $400 \mathrm{ml}$ water, was taken orally by each subject over $45 \mathrm{~s}$. At 18.15 hours on the evenings before metabolic test days 1,16 and 17 all subjects received a meal of similar composition to that described for the evening in Expt 1.

The meals for the two treatments given during this study on days 1,16 and 17 , were the same as those given during Expt 1, with the exception that the orange juice drink was omitted. On days 2-15 the $\mathrm{L}$ and $\mathrm{M}$ breakfasts were given. For lunch and the evening meal two fatty menus were rotated on a $2 \mathrm{~d}$ cycle. The mean composition of the daily menu for the two treatments for days 2 to 15 is given in Table 1 .

\section{Subjects}

A description of the subjects is given in Table 2. All subjects in Expts 1 and 3 attended Papworth Hospital in the afternoon of the day before the commencement and they received the standard evening meal at 18.15 hours. All were similarly accommodated overnight and during subsequent nights before metabolic study days. No abnormal exercise was allowed, other than a gentle short walk to be taken sometime between $2 \mathrm{~h}$ and $4 \mathrm{~h}$ after the commencement of breakfast and lunch in Expt 1 and during the morning of Expt 3. In Expt 2 all subjects fasted from 20.00 hours on the day before the experiment and the subjects remained within the ward throughout the study, no abnormal exercise being permitted.

\section{Lipid metabolite measurements}

In Expt 1 an indwelling antecubital vein cannula was fitted at 07.30-08.00 hours each day, Tuesday to Friday, and removed each evening. Blood samples $(10 \mathrm{ml})$ were taken with

Table 2. Expts 1, 2 and 3. Characteristics of the subjects

\begin{tabular}{|c|c|c|c|c|}
\hline & Mean & SD & Minimum & Maximum \\
\hline \multicolumn{5}{|l|}{ Expts 1 and $2:$ men $(n$ 12) } \\
\hline $\mathrm{BMI}\left(\mathrm{kg} / \mathrm{m}^{2}\right)$ & 26.0 & 3.40 & $21 \cdot 2$ & $30 \cdot 3$ \\
\hline Age (years) & $56 \cdot 6$ & $6 \cdot 31$ & $47 \cdot 1$ & 64.9 \\
\hline Weight (kg) & 80.9 & 14.98 & $60 \cdot 0$ & $100 \cdot 0$ \\
\hline Fasting plasma TAG (mmol/l) & $1 \cdot 15$ & 0.37 & 0.9 & 1.5 \\
\hline Fasting plasma total cholesterol $(\mathrm{mmol} / \mathrm{l})$ & 6.4 & 0.70 & $5 \cdot 5$ & $7 \cdot 4$ \\
\hline \multicolumn{5}{|l|}{ Expts 1 and 2: women $(n 8)$} \\
\hline BMI $\left(\mathrm{kg} / \mathrm{m}^{2}\right)$ & $27 \cdot 4$ & 4.53 & $23-9$ & $35 \cdot 8$ \\
\hline Age (years) & 52.4 & 9.41 & 39.7 & $64 \cdot 0$ \\
\hline Weight (kg) & $72 \cdot 6$ & 12.73 & $60 \cdot 5$ & 97.5 \\
\hline Fasting plasma TAG (mmol/1) & 1.19 & 0.51 & 0.9 & 1.7 \\
\hline Fasting plasma total cholesterol $(\mathrm{mmol} / \mathrm{l})$ & 6.4 & 0.58 & 5.8 & $7 \cdot 4$ \\
\hline \multicolumn{5}{|l|}{ Expt 3: men $(n 12)$} \\
\hline BMI $\left(\mathrm{kg} / \mathrm{m}^{2}\right)$ & $26 \cdot 0$ & $3 \cdot 28$ & 20.9 & $30 \cdot 8$ \\
\hline Age (years) & $55 \cdot 3$ & $8 \cdot 37$ & 41 & 65 \\
\hline Weight (kg) & 83.5 & 14.01 & $62-0$ & $103 \cdot 0$ \\
\hline Fasting plasma TAG (mmol/l) & 1.52 & 0.56 & 0.86 & 2.81 \\
\hline Fasting plasma total cholesterol $(\mathrm{mmol} / \mathrm{l})$ & $5 \cdot 8$ & 0.81 & $4 \cdot 2$ & 7.2 \\
\hline
\end{tabular}


times labelled (1) to (9), at: $0(1), 30(2), 60$ (3), 120 (4) and 265 (5) min after the start of breakfast, and $0(5), 30(6), 60(7), 120(8)$, and $265(9)$ min after the start of lunch. Time point (5) fulfilled the dual purpose of being the last post-breakfast sample and the immediate prelunch sample.

On each occasion in Expt 1 the subject was seated for $5 \mathrm{~min}$ before and during phlebotomy, the cannula was flushed with saline and the first sample discarded. Blood samples were treated with lithium heparin apart from those for general haematology and NEFA measurements, which were treated with fluoride-EDTA. The initial processing of all blood samples occurred within $1 \mathrm{~h}$ of collection. Where plasma analyses were not undertaken immediately samples were held at $-70^{\circ}$ until analysed. All samples for a particular variable from a given day were measured in the same assay run.

Plasma TAG was measured on a Hitachi 717 instrument (Boehringer Mannheim UK Ltd, Lewes, East Sussex), as the difference between total and free plasma glycerol, using a kit (Sigma Diagnostics, Poole, Dorset), employing a colorimetric reaction before and after enzymic hydrolysis of the TAG. NEFA were measured by a colorimetric reaction following the formation of acyl-CoA, on a Hitachi 911 instrument, using a kit (Wako Chemicals GmbH, Neuss, Germany). Plasma cholesterol, other than HDL-cholesterol, was removed by precipitation with phosphotungstic acid and $\mathbf{M n C l}_{2}$. The $\mathrm{HDL}$-cholesterol was then measured using a kit (Instrumentation Laboratory SpA, Milan, Italy), except that the reagent was prepared in our laboratory and calibrated against the Boehringer Mannheim reagent no. 543004. The intra-assay coefficients of variation for the determinations of total glycerol, free glycerol, TAG, NEFA and HDL-cholesterol were respectively: 0.9, 3.6, 3.7, 2.2 and $1.1 \%$

In Expt 2 four blood samples were drawn morning and afternoon at 0, 20, 38, and 60 min following the commencement of eating. Eight further blood samples were taken over $40 \mathrm{~min}$ from the start of the Intralipid infusion, both morning and afternoon. These sixteen samples were drawn from an antecubital vein in the opposite arm to that used for infusion, using Wallace (H.G. Wallace Ltd, Colchester, Essex) and Venflon (BOC Ohmeda AB, Helsinborg, Sweden) indwelling cannulas. Using a Cecil spectrophotometer (Cecil Instruments Ltd, Milton, Cambs.) the light absorbance at $340 \mathrm{~nm}$ of each plasma sample from a subject was measured and from this absorbance the subject's zero time plasma absorbance was subtracted as a blank. The resulting difference was assessed against a standard curve formed from dilutions of Intralipid in saline in the range $0-5 \%$ of the undiluted material. Thus, the plasma Intralipid concentrations were recorded as $\%$ Intralipid in plasma. The rate of Intralipid clearance was measured as the mean decrease per min in plasma Intralipid concentration, where this is expressed as \% undiluted Intralipid. The other procedures for blood analysis were those used in Expt 1.

In Expt 3 on days 1, 16 and 17 the procedure was similar to that followed for Expt 1, with the exception that eleven blood samples were taken daily in Monovet gel tubes (Sarstedt Ltd, Beaumont Leys, Leicester) and held at $2^{\circ}$ to $4^{\circ}$. All samples were processed within $30 \mathrm{~min}$ of collection. The means of each individual's responses for a characteristic on days 16 and 17 were used for statistical analysis.

\section{Statistical methods}

Responses for all repeated measurement variables were summarized at individual subject level by area under the curve (AUC), calculated by applying the trapezium rule for time points 1-5 and 5-9 for morning and afternoon respectively, in Expt 1 (Altman, 1991). The baseline for this calculation was zero. Incremental AUC (IAUC) were also calculated, for 
which the baselines were time 1 for time points $1-5$ and time 5 for time points $5-9$. The baselines for the IAUC in Expt 3 were the pre-breakfast values for post-lunch responses and pre-GTT values for the GTT responses. Multiple regression analyses, including subject as a factor, allowed comparisons to be made between diets and time of day in Expt 1. All computations were carried out with SPSS for Windows software (Statistical Package for the Social Sciences, Version 6.1, 1993, SPSS UK Ltd).

\section{Ethical considerations}

The protocols for the experiments were approved by the Huntingdon Area Medical Ethics Committee and all subjects gave informed written consent to participate.

\section{RESULTS}

\section{Expt 1}

The AUC for two of the response variables in Expt 1, after breakfast and after lunch within sex, are given in Table 3. For these measurements the baseline value was zero. For IAUC the baseline values were the pre-meal values, i.e. time 1 for the morning measurement and time 5 for the afternoon measurement.

Plasma triacylglycerols. For treatments MM and LL the AUC for plasma TAG measured in the afternoon exceeded that measured in the morning (Fig. 1, Table 3), owing to raised pre-lunch (time 5) plasma concentrations within each of these treatments. The difference between morning and afternoon AUC among male subjects was particularly prominent for treatment MM $(P=0.001)$. The main effects for the comparisons AUC MM $v$. LL and morning AUC $v$. afternoon AUC over these two treatments were both significant $(P=0.0005)$. The plasma TAG AUC for treatment LM in the afternoon was greater than that for treatment MM $(P=0 \cdot 02)$, although the afternoon AUC for LM cannot be fully

Table 3. Expt 1. Areas under the curve (AUC) for triacylglycerols (TAG) and HDL-cholesterol (mmol/l.min) and incremental AUC (IAUC) for TAG ( $\mathrm{mmol} / \mathrm{l.min}$ ) in male and female subjects followed for 265 min after a breakfast meal (am) and a lunch meal (pm)*

(Mean values with their standard errors)

\begin{tabular}{|c|c|c|c|c|c|c|c|c|c|}
\hline & \multirow[b]{3}{*}{ Treatment } & \multicolumn{4}{|c|}{ Males (n 6) } & \multicolumn{4}{|c|}{ Females $(n 6)$} \\
\hline & & \multicolumn{2}{|c|}{ am } & \multicolumn{2}{|c|}{$\mathrm{pm}$} & \multicolumn{2}{|c|}{ am } & \multicolumn{2}{|c|}{ pm } \\
\hline & & Mean & SE & Mean & SE & Mean & SE & Mean & SE \\
\hline \multirow[t]{4}{*}{ TAG, AUC } & $\mathrm{LL}$ & 341 & 52 & 373 & 53 & 284 & 29 & 337 & 36 \\
\hline & $\mathbf{M M}$ & 442 & 74 & 569 & 82 & 344 & 24 & 394 & 30 \\
\hline & NM & 358 & 56 & 392 & 54 & 280 & 35 & 328 & 33 \\
\hline & LM & 365 & 57 & 467 & 64 & 304 & 28 & 386 & 42 \\
\hline \multirow[t]{4}{*}{ TAG, IAUC } & LL & -14 & 11 & 33 & 6 & 31 & 4 & 17 & 11 \\
\hline & MM & 45 & 18 & 27 & 31 & 77 & 9 & -38 & 21 \\
\hline & NM & -4 & 6 & 46 & 9 & 3 & 7 & 63 & 7 \\
\hline & LM & -14 & 31 & 94 & 19 & 31 & 9 & 54 & 13 \\
\hline \multirow[t]{4}{*}{ HDL-cholesterol, AUC } & $\mathrm{LL}$ & 251 & 46 & 248 & 42 & 294 & 15 & 282 & 15 \\
\hline & $\mathbf{M M}$ & 237 & 35 & 227 & 36 & 281 & 19 & 274 & 21 \\
\hline & NM & 257 & 50 & 251 & 47 & 292 & 12 & 289 & 12 \\
\hline & LM & 247 & 36 & 243 & 40 & 295 & 22 & 282 & 22 \\
\hline
\end{tabular}

LL, high-carbohydrate breakfast and lunch; MM, moderately high-fat breakfast and lunch; NM, no breakfast, moderately high-fat lunch; LM, high-carbohydrate breakfast, moderately high-fat lunch.

*For details of procedures, see pp. 376-380. 
evaluated as the peak response may not have been reached by the time of the last daily blood sampling (time 9). The plasma TAG IAUC values for morning $v$. afternoon did not differ significantly for treatments LL and MM, as a consequence of the high pre-lunch TAG concentrations. Moreover, the plasma TAG concentration decreased from $1 \mathrm{~h}$ after lunch in treatment MM, whereas it rose throughout the morning in that treatment, as it did throughout the afternoon within treatments NM and LM. The change seen between $2.0 \mathrm{~h}$ and $4.42 \mathrm{~h}$ postprandially in the afternoon for treatment MM was significantly different from that seen between the same times in the morning $(P=0.0005)$. The steep decline in plasma TAG concentration between collections 8 and 9 is in contrast to the rise between collections 4 and 5, and therefore the changes were compared (Fig. 1). The mean rates of change, for both sexes combined, between these two collection times were: $+0.186 \mathrm{mmol} / 1$ per $\mathrm{h}$ in the morning and $-0.079 \mathrm{mmol} / 1$ per $\mathrm{h}$ in the afternoon (difference, $P=0.01$ ). Within treatment LL the same comparison approached significance $(P=0.068)$. The rapid decline in plasma TAG concentration during the afternoon of treatment MM, combined with the high pre-lunch concentration, caused the afternoon IAUC for MM to be negative (in contrast to the large positive value for the morning IAUC) and less than the afternoon IAUC values for treatments NM and LM $(P=0.02)$.

Plasma non-esterified fatty acids and free glycerol. The mean postprandial concentrations of TAG related well to those of plasma NEFA, as measured by AUC, although the postprandial time course for plasma NEFA and for free glycerol was an initial decrease in concentration, followed by a late rise (Figs. 2 and 3 ). The mean postprandial concentrations for TAG and NEFA after lunch were particularly high for males in treatment MM (Tables 3 and 4). The NEFA AUC response was higher for MM after lunch than for the other three high-fat meals: MM morning $(P=0.0001)$, NM afternoon

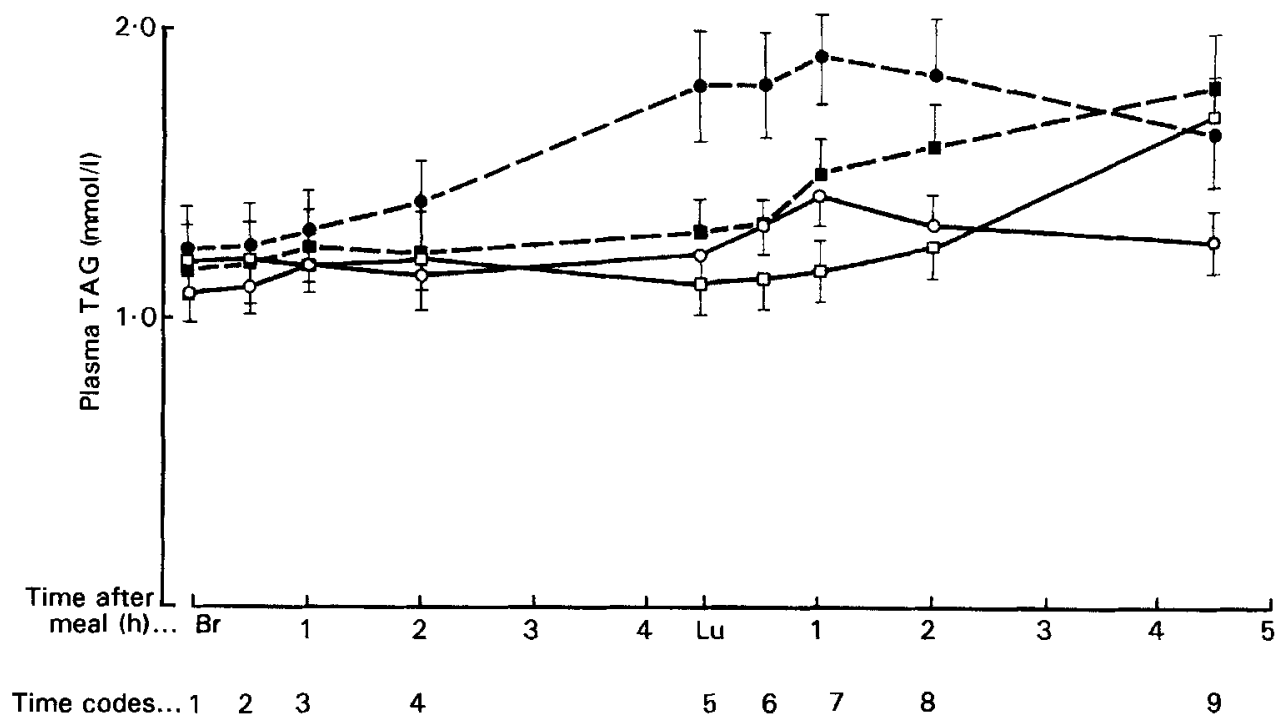

Fig. 1. Expt 1. Mean plasma triacylglycerol (TAG) concentrations of healthy volunteers measured over a period of $4.42 \mathrm{~h}$ following breakfast $(\mathrm{Br})$ and lunch $(\mathrm{Lu})$ meals of different composition. Treatments were: $(\mathrm{O})$, highcarbohydrate breakfast and lunch, LL; (O), moderately high-fat breakfast and lunch, MM; ( $\square$ ), no breakfast, moderately high-fat lunch, NM; $(\square)$, high-carbohydrate breakfast, moderately high-fat lunch, LM. Values are means for twelve subjects, with their standard errors represented by vertical bars. For details of procedures, see pp. 376-380. For main effects: the area under the curve (AUC) for treatment MM was greater than that for LL $(P=0.0005)$, and the AUC for the morning was less than that for the afternoon $(P=0.0005)$. 


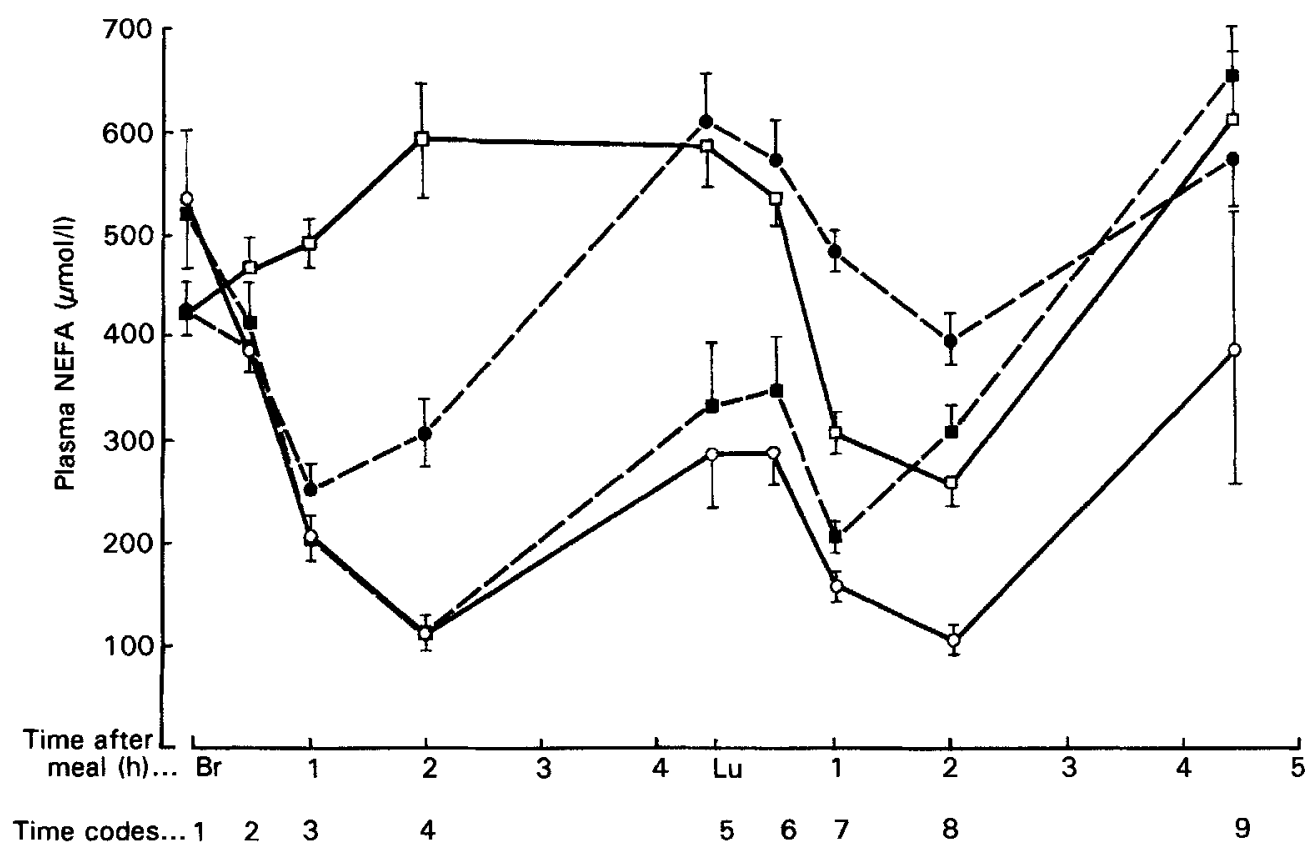

Fig. 2. Expt 1. Mean plasma non-esterified fatty acid (NEFA) concentrations of healthy volunteers measured over a period of $4.42 \mathrm{~h}$ following breakfast $(\mathrm{Br})$ and lunch $(\mathrm{Lu})$ meals of different composition. Treatments were: $(\mathrm{O})$, highcarbohydrate breakfast and lunch, LL; (Q), moderately high-fat breakfast and lunch, MM; $(\square)$, no breakfast, moderately high-fat lunch, NM; (ם), high-carbohydrate breakfast, moderately high-fat lunch, LM. Values are means for twelve subjects, with their standard errors represented by vertical bars. For details of procedures see pp. 376-380. The area under the curve for treatment $\mathrm{MM}$ after lunch was greater than those for the other three treatments for the same period, $P=0.001$.

$(P=0.001)$ and LM afternoon $(P=0.0001)$. The cereal breakfast lowered the afternoon NEFA AUC in treatment LM, notably amongst males. However, there was no significant difference in NEFA concentrations between morning and afternoon for treatment LL (Fig. 2).

The plasma free glycerol AUC values were similar to those for NEFA, with similar levels of significance, apart from the response to treatment $\mathrm{NM}$ in the morning, for which there were expectedly high NEFA concentrations, and the glycerol AUC response to NM after lunch was less than that to LM after lunch (Fig. 3 and Table 4). This is likely to have resulted from the much greater concentrations of plasma glucose seen after breakfast in treatment LM (results not shown).

Plasma HDL-cholesterol. Plasma HDL-cholesterol concentration was previously demonstrated to be inversely related to TAG response (Frape \& Jones, 1995). Similarly in the present study the postprandial HDL-cholesterol AUC was marginally lower in the afternoon than in the morning in both treatments LL and MM $(P=0.072)$ and lower over the day in treatment MM than in LL $(P=0.002$; Table 3). The comparison amongst the fatty meals indicated that the AUC for HDL-cholesterol was lower for treatment MM after lunch than for NM after lunch $(P=0.02)$, but the difference between the afternoon AUC for MM and LM did not attain significance, $(P=0.06)$. The HDL-cholesterol concentration was considerably higher amongst females than amongst males (Table 3 ), as previously found (Frape \& Jones, 1995). 


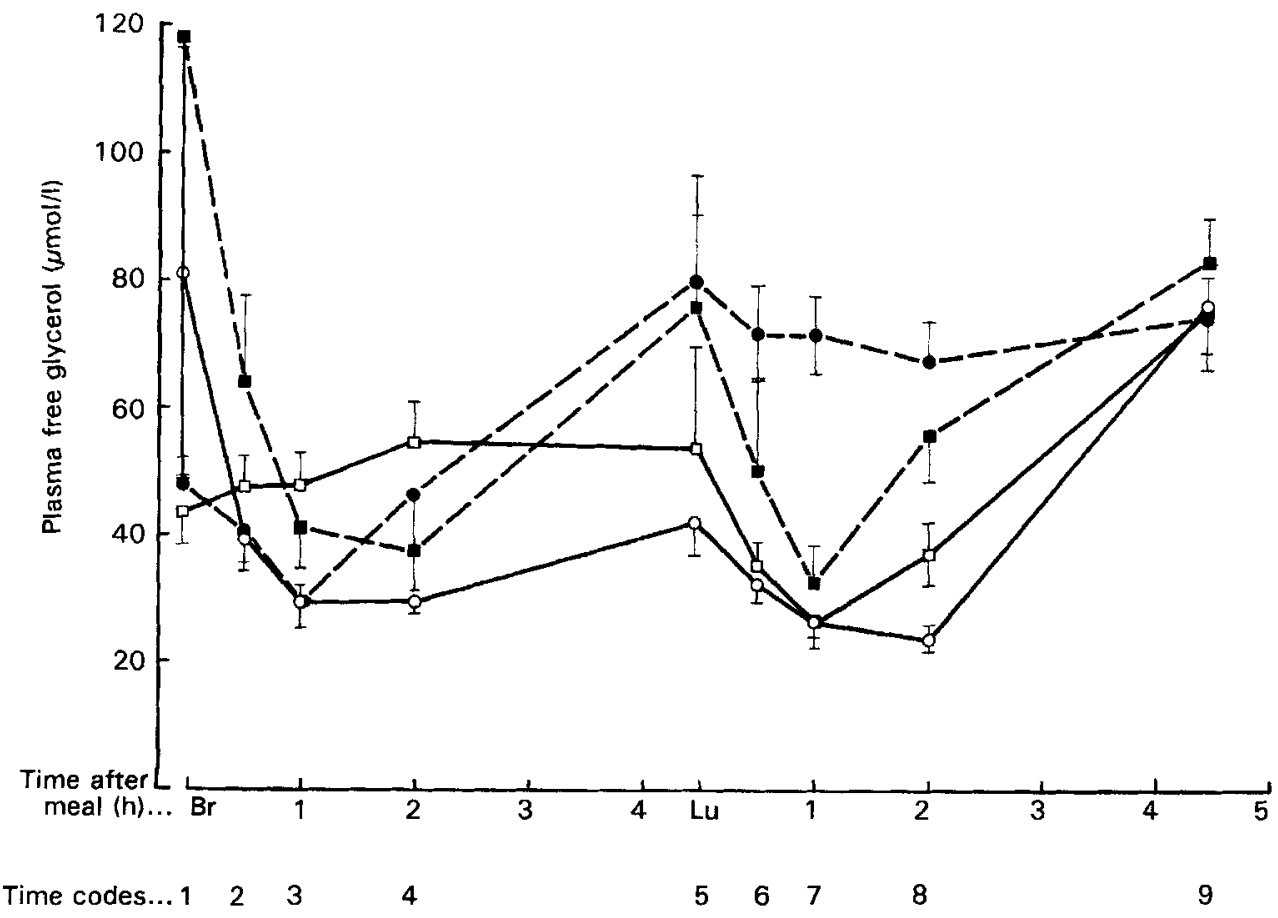

Fig. 3. Expt 1. Mean plasma free glycerol concentrations of healthy volunteers measured over a period of $4.42 \mathrm{~h}$ following breakfast $(\mathrm{Br})$ and lunch $(\mathrm{Lu})$ meals of different composition. Treatments were: $(\mathrm{O})$, high-carbohydrate breakfast and lunch, LL; (O), moderately high-fat breakfast and lunch, MM; $\square$ ), no breakfast, moderately high-fat lunch, NM; (E), high-carbohydrate breakfast, moderately high-fat lunch, LM. Values are means for twelve subjects, with their standard errors represented by vertical bars. For details of procedures, see pp. 376-380. The area under the curve (AUC) for treatment MM after lunch was greater than those for the other three treatments for the same period, $P=0.01$. The AUC for treatment $\mathrm{LM}$ after lunch was greater than that for NM after lunch, $P=0.01$.

Table 4. Expt 1. Areas under the curve (AUC; mmol/l.min) for free glycerol and non-esterified fatty acids (NEFA) in male and female subjects followed for 265 min after a breakfast meal (am) and a lunch meal (pm)*

(Mean values with their standard errors)

\begin{tabular}{|c|c|c|c|c|c|c|c|c|c|}
\hline \multirow[b]{3}{*}{ AUC } & \multirow[b]{3}{*}{ Treatment } & \multicolumn{4}{|c|}{ Males ( $n$ 6) } & \multicolumn{4}{|c|}{ Females $(n 6)$} \\
\hline & & \multicolumn{2}{|c|}{$\mathrm{am}$} & \multicolumn{2}{|c|}{$\mathrm{pm}$} & \multicolumn{2}{|c|}{ am } & \multicolumn{2}{|c|}{$\mathrm{pm}$} \\
\hline & & Mean & SE & Mean & $\mathrm{SE}$ & Mean & SE & Mean & $\mathrm{SE}$ \\
\hline \multirow[t]{4}{*}{ Free glycerol } & $\mathbf{L L}$ & $10 \cdot 3$ & 1.9 & $13 \cdot 2$ & 4.6 & 9.7 & 0.7 & 8.7 & 1.0 \\
\hline & $\mathrm{MM}$ & 13.6 & 1.5 & 21.7 & 2.3 & $14 \cdot 6$ & $2 \cdot 3$ & $16 \cdot 8$ & 1.8 \\
\hline & NM & 15.9 & $3 \cdot 1$ & $12 \cdot 2$ & 1.5 & 11.8 & 1.2 & 12.9 & 1.4 \\
\hline & LM & $18 \cdot 2$ & $5 \cdot 5$ & 18.5 & $3 \cdot 1$ & 12.5 & $3 \cdot 0$ & 13.9 & 1.5 \\
\hline \multirow[t]{4}{*}{ NEFA } & LL & 68.7 & $6 \cdot 3$ & $70-8$ & $20 \cdot 4$ & 59.5 & 7.4 & $51 \cdot 0$ & 8.8 \\
\hline & MM & 98.5 & 3.6 & 137.7 & $10 \cdot 2$ & 115.6 & 11.7 & 127.8 & $6 \cdot 2$ \\
\hline & NM & $151 \cdot 2$ & $18 \cdot 1$ & $112 \cdot 0$ & 6.0 & $145 \cdot 3$ & 11.5 & 112.1 & 10.0 \\
\hline & LM & 69.2 & 6.8 & 98.4 & 10.4 & 66.6 & 11.9 & 111.4 & $11 \cdot 7$ \\
\hline
\end{tabular}

*For details of procedures, see pp. 376-380. 


\section{Expt 2}

The maximum mean plasma concentration of Intralipid occurred at approximately $4.5 \mathrm{~min}$ after the mean infusion time and $80 \%$ of the infused dose of Intralipid was cleared in $40 \mathrm{~min}$. Between 4.5 and $40 \mathrm{~min}$ post-infusion the clearance rates were log-linear and the residual variation was decreased by transposing the $\mathrm{x}$ axis to $\log$ time. Most of the variation in plasma Intralipid concentration was then accounted for by regression $\left(R 0.96 ; R^{2} 0.92\right.$, $P<0.00005$ ) and the comparison of morning $v$. afternoon clearance rates on log time was significant $(P=0.024)$. Within-subject $t$ tests indicated that in all but one subject the clearance rate was faster in the afternoon than in the morning.

\section{Expt 3}

There was no significant treatment difference (MM v. LM) in the decrease in fasting plasma TAG concentration over the $17 \mathrm{~d}$ of the experiment. The changes in fasting plasma TAG from day 1 to days 16 and 17 for treatments MM and LM were: -0.40 and -0.26 mmol/l $(P>0 \cdot 1)$, respectively.

The changes in NEFA AUC, post-lunch pre-GTT, from day 1 to days 16 and 17 were $+19 \mathrm{mmol} / \mathrm{l}$.min for MM and $-7 \mathrm{mmol} / 1 . \mathrm{min}$ for LM $(P=0.025)$. During the GTT plasma NEFA declined linearly with time in both treatments from 16 min following the start of glucose dosing (Table 5 and Fig. 4). The linear rate over $1.5 \mathrm{~h}$ from the peak was -0.229 (SE 0.0154) $\mathrm{mmol} / 1$ per $\mathrm{h}(P=0.00066)$. Also during the GTT there was a large plasma TAG IAUC response on day $1(P=0.001)$ and again on the mean of days 16 and 17 $(P=0.006)$ in both treatments. The IAUC for plasma TAG during the GTT on days 16 and 17 in treatment $\mathrm{LM}$ was greater than the response to that treatment during the immediate post-lunch period and it was greater than that for MM during the GTT ( $P=0.025$; Fig 4$)$. Nevertheless this treatment difference should be accepted with caution, owing to the small number of subjects allocated to each treatment.

Table 5. Expt 3. Incremental areas under the curve (IAUC; mmol/l.min) for plasma triacylglycerols (TAG) and non-esterified fatty acids (NEFA) measured during a $104 \mathrm{~min}$ glucose tolerance test; pre-glucose-tolerance blood samples, taken on day 1 when all subjects received treatment $L M$, provided the baseline values*

(Mean values with their standard errors for six male subjects per treatment. Responses are given as the mean of days 16 and 17 minus day 1 )

\begin{tabular}{|c|c|c|c|c|c|}
\hline \multirow[t]{2}{*}{ Treatment... } & \multicolumn{2}{|c|}{$\mathbf{M M}$} & \multicolumn{2}{|c|}{$\mathbf{L M}$} & \multirow{2}{*}{$\begin{array}{c}\text { Statistical significance } \\
\text { of treatment difference: } P=\emptyset\end{array}$} \\
\hline & Mean & $\mathrm{SE}$ & Mean & SE & \\
\hline \multicolumn{6}{|l|}{$\overline{\mathrm{TAG}}$} \\
\hline IAUC day 1 & 68 & $26 \cdot 8$ & 64 & 9.7 & \\
\hline IAUC days 16 and 17 & 16 & 8.0 & 79 & 19.9 & \\
\hline Difference & -52 & & 15 & & $0.025 \mathrm{LM}>\mathrm{MM}$ \\
\hline \multicolumn{6}{|l|}{ NEFA } \\
\hline IAUC day 1 & -22 & 9.6 & -11 & $2 \cdot 1$ & \\
\hline IAUC days 16 and 17 & -15 & 4.2 & -11 & $3 \cdot 3$ & \\
\hline Difference & 7 & & 0 & & $0.64 \mathrm{MM}>\mathrm{LM}$ \\
\hline
\end{tabular}

*For details of procedures, see pp. 377-380.

$\dagger$ Treatment difference $=(($ days $16+17) / 2)-$ day 1 . 


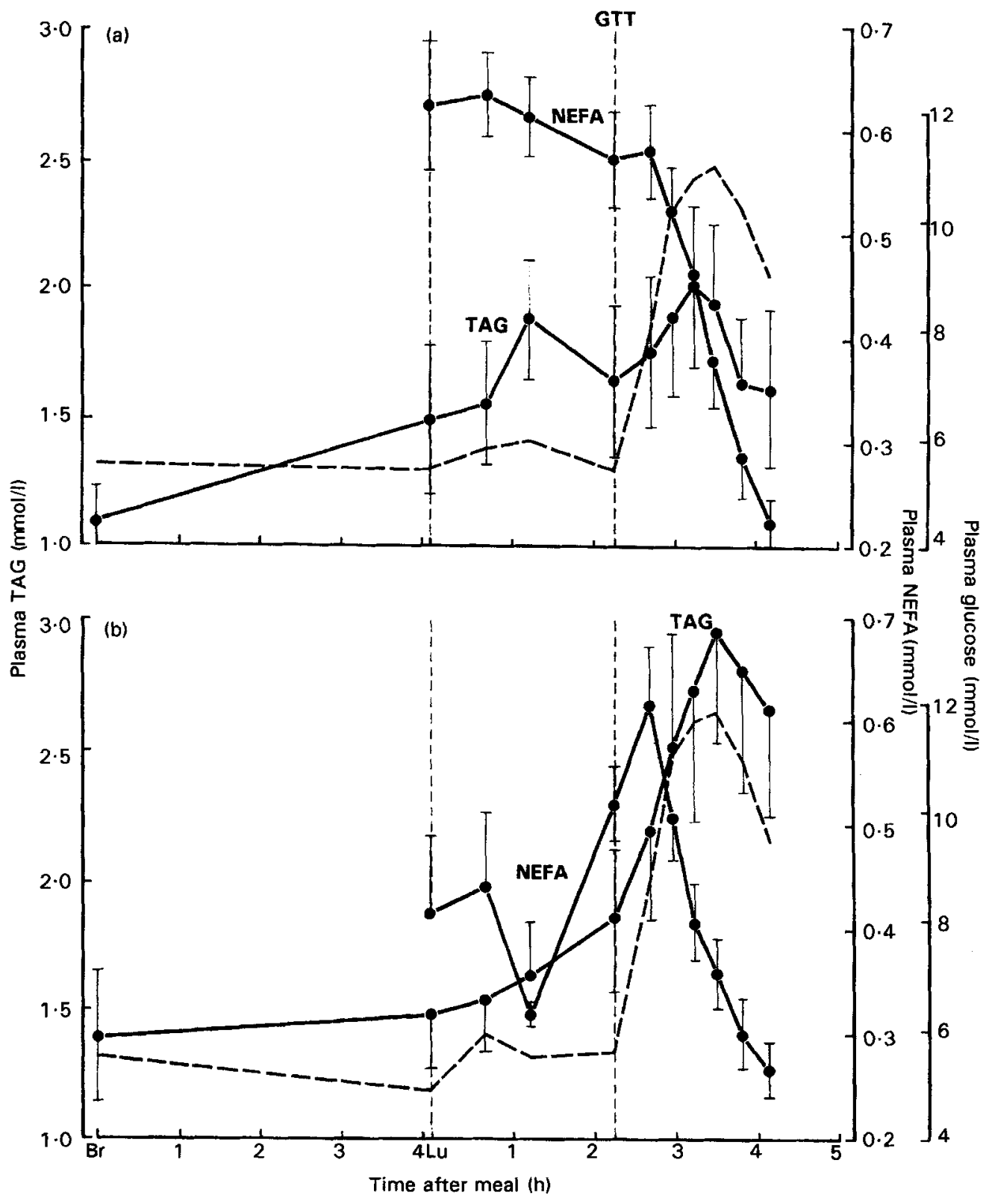

Fig. 4. Expt 3. Plasma concentrations of triacylglycerol (TAG) and non-esterified fatty acids (NEFA) in healthy volunteers measured after consumption of breakfast $(\mathrm{Br})$ and lunch $(\mathrm{Lu})$ meals of different composition. Treatments were: (a) moderately high-fat breakfast and lunch, MM; (b) high-carbohydrate breakfast, moderately high-fat lunch, LM. Values are means of the days 16 and 17 values for six subjects, with their standard errors represented by vertical bars. (- -), mean plasma glucose response curve. GTT, glucose tolerance test. For details of procedures, see pp. $377-$ 380. The post-lunch, pre-GTT incremental area under the curve (IAUC) of TAG for treatment MM was greater than that for LM, $P=0.078$, and the AUC for NEFA for treatment MM was greater than that for $\mathrm{LM}, P=0.025$. The post-GTT LAUC for TAG for treatment LM was greater than that for MM, $P=0.025$. 


\section{DISCUSSION}

\section{Plasma triacylglycerol concentration}

In Expt 2, the tendency for Intralipid to be cleared faster in the afternoon was significant $(P=0.024)$. In seven out of eight subjects the clearance rate was faster in the afternoon. Polyunsaturated fats, as found in Intralipid, are cleared more readily than are saturated fats (Fraser, 1994). Consequently with more-saturated dietary fats, typical of a Western diet, an even more distinct diurnal difference may well have been detected. The increase during the morning in plasma TAG content in the period between $2.0 \mathrm{~h}$ and $4.42 \mathrm{~h}$ after breakfast, compared with the decrease during the corresponding postprandial period in the afternoon, in treatment MM of Expt 1, might indicate a more rapid clearance, a less rapid rate of fatty acid esterification and mobilization, or both effects. The measurements undertaken in Expt 1 were not appropriate to resolve these alternative postulates.

The higher pre-lunch baseline TAG concentrations within treatment MM of Expt 1 and the larger TAG AUC in the afternoon ( $v$. IAUC) compared with the morning are considered to be a consequence of the continued absorption of fat from the morning meal in the afternoon. It has been demonstrated (Fielding et al. 1996) that following a second normal daily meal, a component of the chylomicron TAG response is derived from the first meal. Following the two successive low-fat meals (LL) in Expt 1 the higher plasma TAG concentration seen after lunch also resulted from higher pre-lunch baseline values, apparently combined with a stimulation by carbohydrate of fatty acid esterification and secretion. There is evidence that the replacement of fat with carbohydrate can actually increase the postprandial TAG response of patients with NIDDM and this is interpreted as a stimulation of endogenous apoB-100 TAG synthesis and VLDL-TAG secretion that competes with intestinally derived chylomicrons for clearance (Garg et al. 1988, 1994; Chen et al. 1993, 1995). If carbohydrate had been a more potent stimulant than dietary fat, to a rise in plasma TAG concentration in our healthy volunteers, it would have been expected that treatment LL would have led to higher postprandial concentrations of TAG, and presumably of NEFA, than were caused by treatment MM. In fact the reverse occurred (LL $v$. MM, $P=0.0005$ ). The high circulating concentration of plasma TAG in the afternoon would seem to include both chylomicrons from the two previous meals of the day and TAG resulting from a stimulation of fatty acid esterification by carbohydrate from two meals. However, dietary carbohydrate in Expt 1 had a lesser effect on postprandial plasma TAG concentration than did similar amounts of ME provided as dietary fat for healthy middle-aged volunteers. The studies of Garg et al. $(1988,1994)$ and of Chen $e t$ al. (1995) were all conducted on patients with NIDDM for which the IAUC TAG response was not measured. In all these studies the postprandial increase in plasma TAG concentration, resulting from a high-carbohydrate (low-fat) meal, compared with a high-fat meal, could be substantially accounted for by the fasting differences in plasma TAG. Moreover, the fat compositions of their low- and high-fat diets were dissimilar. The fat supplement, substituting for carbohydrate, was olive oil, rich in monounsaturated fatty acids, which are known to lower fasting plasma TAG, in comparison to the effects of saturated fatty acids (Grundy, 1989). In the present studies the fatty acid compositions of the fats of the $M$ and $L$ treatments were similar (Table 1) and there was no significant treatment difference (MM $v$. LM) in the decrease in fasting plasma TAG concentration over the $17 \mathrm{~d}$ of Expt 3.

In Expt 3 the glucose dose taken in $45 \mathrm{~s}$, and providing $63 \%$ of the ME provided by the lunch, appeared to stimulate an immediate rise in plasma TAG concentration, as the afternoon TAG response curves were different from, and greater than, those observed for these treatments in Expt 1. In healthy subjects plasma TAG concentration typically reaches 
a peak $3 \mathrm{~h}$ after a single moderately fatty meal, but without showing the pattern of response found in Expt 3 (Kashyap et al. 1983; Miettinen, 1987; Cohn et al. 1988; Cohen \& Berger, 1990). Nevertheless there is no conclusive, within-experiment evidence that the Expt 3 TAG response between $2 \mathrm{~h} 20 \mathrm{~min}$ and $4 \mathrm{~h}$ after lunch was a result of the glucose dose, although it is in accord with the evidence referred to earlier, reported by Chen et al. (1993, 1995) for patients with NIDDM. The daily intake by healthy subjects of large amounts of carbohydrate, containing $22-25 \%$ sucrose, stimulates TAG synthesis and release as endogenous apoB-100 VLDL-TAG in the fasting state (Lui et al. 1983) and during the day (Mann \& Truswell, 1972; Truswell, 1994). However, the addition of $50 \mathrm{~g}$, or $100 \mathrm{~g}$, glucose to a meal of cream reduced the serum concentrations of TAG at 2,3,4,6 and $7 \mathrm{~h}$ postprandially (Cohen \& Berger, 1990). This hypotriacylglycerolaemic effect of glucose appeared to reflect delayed gastric emptying and decreased hepatic secretion of TAG that would not have occurred in Expt 3.

Insulin infusion suppresses intracellular hormone sensitive lipase (HSL) and promotes esterification of fatty acids (Frayn, 1993), accounting for the rapid decline in plasma NEFA concentration during the GTT in Expt 3. The large glucose dose and coincidental increases in plasma glucose and TAG concentrations (Fig. 4) are likely to have been associated with an increased availability of $\alpha$-glycerophosphate. Thus, there would have been an increase in fatty acid esterification rather than oxidation, although insulin secretion minimizes VLDL-TAG secretion (Frayn \& Kingman, 1995). The greater TAG response in treatment LM v. MM, following the glucose dose, accords with the apparent delay in TAG clearance observed in the afternoon for treatment LM in Expt 1 (Fig. 1), for which there may be a common cause. Whether this effect results from a greater rate of fatty acid esterification, mobilization of chylomicrons from the intestinal tract during glucose absorption, or to a slower clearance rate of TAG in the afternoon in treatment LM cannot be determined from our observations. The immediacy of the TAG response during the GTT points to accelerated chylomicron mobilization in treatment LM $v$. MM. There may also have been a lack of stimulation of adipose tissue lipoprotein lipase (EC 3.1.1.34; LPL) activity by the low-fat breakfast in treatment LM, or morning fast in treatment NM, for afternoon fat clearance. The IAUC of plasma TAG for LM in the afternoon was threefold that of MM for the same period in Expt 1, a difference especially pronounced in males, but without an attendant rise in plasma NEFA or fall in HDL-cholesterol concentration in LM. It coincided with a relatively low afternoon insulin response by males in treatment LM in both Expts 1 and 3 (to be reported elsewhere). This may have contributed to a lesser stimulation of LPL.

\section{Plasma HDL-cholesterol}

Low plasma HDL-cholesterol concentration is a risk factor for CHD. We previously showed a strong inverse correlation between postprandial TAG response to a high-fat meal and postprandial plasma HDL-cholesterol concentration in healthy middle-aged subjects (Frape \& Jones, 1995). In agreement, Neary et al. (1991) reported that elevated plasma TAG lowered pre- $\beta$ HDL-cholesterol concentration and Chen et al. (1993) observed a negative association between fasting plasma HDL-cholesterol concentration and postprandial TAG concentration in patients with NIDDM. In contrast Syvänne et al. (1993) observed no correlation between postprandial lipaemia and either HDL-cholesterol concentration, or post-heparin LPL activity. In Expt 1 the MM treatment lowered the plasma AUC of HDL-cholesterol, especially in the afternoon when the plasma TAG concentration was highest. Males demonstrated lower circulating levels of HDL- 
cholesterol than females, possibly as a consequence of higher circulating levels of TAG, following both high-fat and high-carbohydrate meals. The HDL-cholesterol AUC was the lowest amongst males on treatment $\mathrm{MM}$ in the afternoon (Table 3) and treatment LM appeared to improve the situation. Lamon-Fava et al. (1994) reported that amongst the elderly (60-100 years) higher intakes of carbohydrate were associated with lower plasma concentrations of HDL cholesterol. Yet in their study it appeared to be the raised plasma TAG concentration that regulated plasma HDL-cholesterol concentration. Thus, it is concluded that the critical factor is the effect of dietary carbohydrate and fat on the circulating TAG level, which regulates plasma HDL-cholesterol concentration by mechanisms previously discussed (Frape \& Jones, 1995).

\section{Plasma non-esterified fatty acids and free glycerol}

The postprandial NEFA responses in the resting subject are the result of the activities of two lipases: (1) adipose tissue LPL, and (2) intracellular HSL. The second of these enzymes may be the principal cause of the characteristic shape of the postprandial plasma NEFA curve (Fig. 2), in accord with the evidence of Frayn et al. (1994) and Zampelas et al. (1994). A meal, with the consequent rise in plasma insulin, suppresses the activity of this enzyme (Van Amelsvoort et al. 1989), causing a fall in NEFA concentration. Approximately $4 \mathrm{~h}$ after a meal, when blood glucose concentration will have declined and postprandial plasma chylomicron concentration increased, there is a rise in NEFA concentration. This rise is probably due to the activity of LPL and the leak-back of NEFA into the circulation (Frayn et al. 1994; Griffiths et al. 1994), and to reinstated intracellular enzyme activity and depot fat hydrolysis. Superimposed on this response our results in Expt 1, given here, and previously discussed (Frape et al. 1994), show that the MM treatment caused higher mean circulating levels of NEFA than occurred with treatment LM, owing presumably to higher mean postprandial TAG concentrations stimulating LPL activity. In Expt 3 the post-lunch pre-GTT NEFA AUC values for the mean of days 16 and 17 in treatments MM and LM indicated a similar response to that in Expt 1 (Fig. 4), that is, much higher values occurred in MM than in LM. Despite a suppression of HSL activity and net movement of fatty acids into adipose tissue (Frayn et al. 1994), the higher plasma concentrations of NEFA and of free glycerol in the afternoon, following two successive fatty meals (MM), especially amongst males in Expt 1 (Table 4), are probably the result of adipose tissue LPL acting on the larger number of chylomicrons, as the cereal breakfast appeared to make no contribution to this. Insulin responses in Expts 1 and 3 are not reported here. There was no significant difference in insulin response between treatments MM and LM after lunch, whereas treatment LM caused a much greater insulin response than $\mathrm{MM}$ in the morning $(P=0.0001)$. Consequently there may have been a relatively greater suppression of the activity of intracellular HSL in treatment LM, contributing to the lower plasma NEFA concentration at the beginning of lunch in both Expts 1 and 3 .

The relatively high plasma concentrations of NEFA in the morning in treatment NM reflect the activity of intracellular HSL, contemporary with fasting plasma glucose and insulin concentrations. Fasting insulin concentrations are sufficient at that time to suppress an increase in plasma glycerol concentration in post-absorptive plasma (Frayn et al. 1994), presumably by promoting gluconeogenesis (Table 4).

\section{CONCLUSIONS}

High-carbohydrate meals led to lower plasma TAG responses than moderately high-fat meals of the same energy content, during $4.5 \mathrm{~h}$ after breakfast and lunch in healthy middle- 
aged volunteers. Treatment LL stimulated a small increase in postprandial plasma TAG concentration, but in the afternoon only.

A high-carbohydrate breakfast, compared with a moderately high-fat breakfast, extended the time over which plasma TAG was elevated after a moderately high-fat lunch. The extent to which this resulted from a retarded afternoon clearance rate for treatment LM $v$. MM, or to a stimulation by LM of afternoon fatty acid esterification and mobilization, requires further investigation.

Plasma TAG concentration was higher in the afternoon than in the morning following the consumption of meals of the same composition, both high or low in fat, at breakfast and at lunch. This led to lower HDL-cholesterol concentrations, especially during the afternoon in males, and to higher afternoon plasma NEFA concentrations, following moderately high-fat meals. In contrast the IAUC TAG response to lunch was lower than that to breakfast and the clearance rate of plasma fat was faster in the afternoon than in the morning.

It is proposed that the higher afternoon NEFA AUC in treatment MM results from increased chylomicron secretion following a second fatty meal of the day and an increased rate of TAG clearance in the afternoon, both stimulating a high rate of NEFA leak-back into the circulation. The afternoon plasma concentration of NEFA following a breakfast and lunch each providing $33 \mathrm{~g}$ mixed fat, was found to be within the range of that reported to cause insulin resistance in isolated hepatocytes.

The relatively short intervals between the three normal meals during the day could mean that the metabolic effects of lunch and an evening meal are affected by the composition of the previous meal.

The authors would like to acknowledge the assistance of Drs J. W. Foote, A. N. Howard, and L. Pandya. They are also most grateful to Mrs J. West for technical assistance and to the volunteer subjects who participated in the studies.

\section{REFERENCES}

Altman, D. G. (1991).Practical Statistics for Medical Research. London: Chapman and Hall.

Baggio, G., Fellin, R., Baiocchi, M. R., Martini, S., Baldo, G., Manzato, E. \& Crepaldi, G. (1980). Relationship between triglyceride-rich lipoprotein (chylomicrons and VLDL) and $\mathrm{HDL}_{2}$ and $\mathrm{HDL}_{3}$ in the post-prandial phase in humans. Atherosclerosis 37, 271-276.

Barbagallo, C. M., Averna, M. R., Amato, S., Davi, G., Pagano, D., Noto, D. \& Notarbartolo, A. (1991). Lipid and apoprotein behaviour after an oral fat load in hypertriglyceridaemia. Diabetes Metabolism 17, 512-519.

Chen, Y.-D. I., Coulston, A. N., Zhou, M.-Y., Hollenbeck, C. B. \& Reaven, G. M. (1995). Why do low-fat highcarbohydrate diets accentuate postprandial lipaemia in patients with NIDDM. Diabetes Care 18, $10-16$.

Chen, Y.-D. I., Swami, S., Skowronski, R., Coulston, A. \& Reaven, G. M. (1993). Differences in postprandial lipemia between patients with normal glucose tolerance and noninsulin-dependent diabetes mellitus. Journal of Clinical Endocrinology and Metabolism 76, 172-177.

Cohen, J. C. \& Berger, G. M. (1990). Effects of glucose ingestion on postprandial lipemia and triglyceride clearance in humans. Journal of Lipid Research 31, 597-602.

Cohn, J. E., McNamara, J. R., Cohn, S. D., Ordovas, J. M. \& Schaefer, E. J. (1988). Postprandial plasma lipoprotein changes in human subjects of different ages. Journal of Lipid Research 29, 469-479.

Fielding, B. A., Callow, J., Owen, R. M., Samra, J. S., Matthews, D. R. \& Frayn, K. N. (1996). Postprandial lipemia: the origin of an early peak studied by specific dietary fatty acid intake during sequential meals. American Joumal of Clinical Nutrition 63, 36-41.

Frape, D. L. \& Jones, A. M. (1995). Chronic and postprandial responses of plasma insulin, glucose and lipids in volunteers given dietary fibre supplements. British Journal of Nutrition 73, 733-751.

Frape, D. L., Williams, N. R., Pickersgill, J., Murrills, R., Palmer, C. \& Fletcher, R. J. (1994). The postprandial response to high-fat, low-carbohydrate and low-fat, high-carbohydrate meals providing the same amounts of energy in subjects at risk of heart disease. Proceedings of the Nutrition Society 53, 221A.

Fraser, G. E. (1994). Diet and coronary heart disease: beyond dietary fats and low-density-lipoprotein cholesterol. American Journal of Clinical Nutrition 59, Suppl., 1117S-1123S. 
Frayn, K. N. (1993). Insulin resistance and lipid metabolism. Current Opinion in Lipidology 4, 197-204.

Frayn, K. N. \& Kingman, S. M. (1995). Dietary sugars and lipid metabolism in humans. American Journal of Clinical Nutrition 62, Suppl., 250S-263S.

Frayn, K. N., Shadid, S., Hamlani, R., Humphreys, S. M., Clark, M. L., Fielding, B. A., Boland, O. \& Coppack, S. W. (1994). Regulation of fatty acid movement in human adipose tissue in the postabsorptive-topostprandial transition. American Journal of Physiology 266, E308-E317.

Garg, A., Bantle, J. P., Henry, R. R., Coulston, A. M., Griver, K. A., Raatz, S. K., Brinkley, L., Chen, Y.-D. I., Grundy, S. M., Huet, B. A. \& Reaven, G. M. (1994). Effects of varying carbohydrate content of diet in patients with non-insulin-dependent diabetes mellitus. Journal of the American Medical Association 271, $1421-1428$.

Garg, A., Bonanome, A., Grundy, S. M., Zhang, Z.-J. \& Unger, R. H. (1988). Comparison of a highcarbohydrate diet with a high-monounsaturated-fat diet in patients with non-insulin-dependent diabetes mellitus. New England Journal of Medicine 319, 829-834.

Griffiths, A. J., Humphreys, S. M., Clark, M. L., Fielding, B. A. \& Frayn, K. N. (1994). Immediate metabolic availability of dietary fat in combination with carbohydrate. American Journal of Clinical Nutrition 59, 5359.

Grundy, S. M. (1989). Monounsaturated fatty acids and cholesterol metabolism: implications for dietary recommendations. Journal of Nutrition 119, 529-533.

Kashyap, M. L., Barnhart, R. L., Srivastava, L. S., Perisutti, G., Allen, C., Hogg, E., Glueck, C. J. \& Jackson, R. L. (1983). Alimentary lipemia: plasma high density lipoproteins and apolipoproteins $\mathrm{CII}$ and $\mathrm{CIII}$ in healthy subjects. American Journal of Clinical Nutrition 37, 233-243.

Lamon-Fava, S., Jenner, J. L., Jacques, P. F. \& Schaefer, E. J. (1994). Effects of dietary intakes on plasma lipids, lipoproteins, and apolipoproteins in free-living elderly men and women. American Journal of Clinical Nutrition 59, 32-41.

Lindén, T., Bondjers, G., Karlsson, T. \& Wiklund, O. (1994). Serum triglycerides and HDL cholesterol - major predictors of long-term survival after coronary surgery. European Heart Journal 15, 747-752.

Lui, G. C., Coulston, A. M. \& Reaven, G. M. (1983). Effect of high-carbohydrate-low-fat diets on plasma glucose, insulin and lipid responses in hypertriglyceridemic humans. Metabolism 32, 750-753.

Mann, J. I. \& Truswell, A. S. (1972). Effects of isocaloric exchange of dietary sucrose and starch on fasting serum lipids, postprandial insulin secretion and alimentary lipaemia in human subjects. British Journal of Nutrition 27, 395-405.

Miettinen, T. A. (1987). Dietary fibre and lipids. American Journal of Clinical Nutrition 45, 1237-1242.

Neary, R., Bhatnager, D., Durrington, P., Ishola, M., Arrol, S. \& Mackness, M. (1991). An investigation of the role of lecithin: cholesterol acyltransferase and triglyceride-rich lipoproteins in the metabolism of pre-beta high density lipoproteins. Atherosclerosis 89, 35-48.

Randle, P. J., Garland, P. B., Hales, C. N. \& Newsholme, E. A. (1963). The glucose fatty-acid cycle. Its role in insulin sensitivity and the metabolic disturbances of diabetes mellitus. Lancet 1, 785-789.

Sidery, M. B., Gallen, I. W. \& Macdonald, I. A. (1990). The initial physiological responses to glucose ingestion in normal subjects are modified by a $3 \mathrm{~d}$ high-fat diet. British Journal of Nutrition 64, 705-713.

Smith, U. (1994). Carbohydrates, fat, and insulin action. American Journal of Clinical Nutrition 59, Suppl., 686S-689S.

Svedberg, J., Björntorp, P., Lönnroth, P. \& Smith, U. (1991). Prevention of inhibitory effect of free fatty acids on insulin binding and action in isolated rat hepatocytes by Etomoxir. Diabetes 40, 783-786.

Svedberg, J., Björntorp, P., Smith, U. \& Lönnroth, P. (1990). Free-fatty acid inhibition of insulin binding, degradation, and action in isolated rat hepatocytes. Diabetes 39, 570-574.

Syvänne, M., Vuorinen-Markkola, H., Hilden, H. \& Taskinen, M.-R. (1993). GeMibrozil reduces postprandial lipemia in non-insulin-dependent diabetes mellitus. Arteriosclerosis and Thrombosis 13, 286-295.

Truswell, A. S. (1994). Food carbohydrates and plasma lipids - an update. American Joumal of Clinical Nutrition 59 Suppl., 710 S-718S.

Van Amelsvoort, J. M. M., Van Stratum, P., Kraal, J. H., Lussenburg, R. N. \& Houtsmuller, U. M. T. (1989). Effects of varying the carbohydrate: fat ratio in a hot lunch on postprandial variables in male volunteers. British Journal of Nutrition 61, 267-283.

Zampelas, A., Williams, C. M., Morgan, L. M., Wright, J. \& Quinlan, P. T. (1994). The effect of triacylglycerol fatty acid positional distribution on postprandial plasma metabolite and hormone responses in normal adult men. British Journal of Nutrition 71, 401-410. 